\title{
Твердотельные СвЧ-переключатели средней и большой мощности
}

\section{Часть 1}

\author{
В. Кочемасов, к. т.н. ${ }^{1}$, С. Дингес, к. т. н. ${ }^{2}$, В. Шадский, к. т. н. ${ }^{3}$
}

\begin{abstract}
СВЧ-переключатели широко используются в современных электронных устройствах. Во многих приложениях необходимы переключатели, рассчитанные на достаточно высокую мощность входных сигналов. Статья посвящена твердотельным переключателям средней и большой мощности, выполненным по различным технологиям.
\end{abstract}

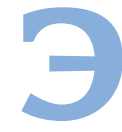

лемент тракта, обеспечивающий изменение направления передачи СвЧ-энергии, называется переключателем сигналов. Диапазон рабочих частот, вносимые потери, развязка, скорость переключения и величина коммутируемой мощности являются основными характеристиками переключателей. Современные переключатели (ферритовые [1], электромеханические [2], твердотельные [3], [4] и МЭМС [5]) обеспечивают переключение сигналов с частотой до 100 гГц и более, вносимые потери в доли децибел, развязку до 100 и более децибел, скорость переключения в доли наносекунд при входных мощностях от сотых долей ватта до десятков, а то и сотен киловатт. Безусловно, в рамках одного изделия такие предельные характеристики не достигаются. Например, названные предельные мощности входных сигналов характерны для ферритовых и электромеханических переключателей в волноводном исполнении. Достаточно большие - до нескольких сотен, а то и тысяч ватт - пиковые мощности реализуются в электромеханических и твердотельных переключателях коаксиального исполнения.

Современные твердотельные переключатели вполне могут конкурировать с электромеханическими переключателями в коаксиальном исполнении по уровню вносимых потерь, величине развязки, диапазону рабочих частот, а также по допустимому уровню мощности.

В составе радиотехнических систем переключатели могут решать разные задачи, в том числе и такие, в которых высоких требований к уровню переключаемой мощности не предъявляется. Однако, в радиолокационных или связных системах с временным разделением каналов при попеременном подключении к одной или нескольким антеннам приемо-передающих модулей

ООО «Радиокомп», генеральный директор.

МтусИ, доцент.

АО «Микро-Вис», заместитель генерального директора по науке. требования к допустимой переключаемой мощности становятся приоритетными.

При рассмотрении твердотельных переключателей будем различать переключатели средней (от 0,1 до 10 Вт) и большой (более 10 Вт) мощности. Для оценки мощностных характеристик переключателей используются разные понятия.

Допустимая входная мощность коммутации $\mathrm{P}_{\text {доп }}$ (power handling) обычно указывается в технических описаниях (data sheets) в качестве предельно-допустимого значения. Существуют два ее определения: максимальная мощность, при которой переключатель еще функционирует без деградации своих характеристик (full performance); максимальная мощность, при которой переключатель не выходит из строя, но характеристики его деградируют. В зависимости от вида переключаемого сигнала различают также непрерывную $P_{\text {н }}$ и импульсную $P_{\text {и }}$ допустимые мощности. Последняя обычно приводится вместе с указанием длительности импульсов $T_{\text {и }}$ и их скважности $Q$. Для импульсных сигналов вводится также понятие средней допустимой мощности $P_{\text {ср }}$ за период повторения.

Допустимая мощность также существенно зависит от того, происходит переключение при наличии или отсутствии сигнала на входе переключателя. В первом случае переключение называют горячим, а во втором - холодным (hot and cold switching). Для этих предельно допустимых мощностей, учитывающих способ переключения, вводятся обозначения $\mathrm{P}_{г}$ и $\mathrm{P}_{\mathrm{x}}$ соответственно.

Как и для многих других типов изделий, обеспечивающих усиление или преобразование сигналов, для переключателей вводят понятия, характеризующие их линейность. Среди них $\mathrm{P}_{0,1 д 5}$ и $\mathrm{P}_{1 д Б}$, определяющие степень отклонения от линейного закона зависимости $\mathrm{P}_{\text {вых }}$ от $\mathrm{P}_{\text {вх }}$ а также два более информативных с точки зрения меры нелинейности исследуемых изделий параметра IIP2 и IIP3, характеризующие величину возникающих интермодуляционных искажений 2-го и 3-го порядков. 


\section{ОСОБЕННОСТИ ПРОЕКТИРОВАНИЯ МОЩНЫХ СВЧ-ПЕРЕКЛЮЧАТЕЛЕЙ}

В современных СВЧ-переключателях в качестве активных приборов применяются кремниевые и арсенид-галлиевые ріп-диоды, арсенидгаллиевые и нитрид-галлиевые полевые НЕМТ-транзисторы, а также кМОП-транзисторы с использованием технологий кремний на изоляторе (КНИ) и кремний на сапфиpe (KHC).

Каждый из этих активных приборов имеет свои особенности с точки зрения получения оптимальных параметров СВЧ-переключателей. Наиболее перспективными на сегодняшний день являются переключатели на GaN полевых транзисторах и кремниевых КМОП-транзисторах, позволяющиедобиться максимальных уровней коммутируемой мощности, особенно в верхней части СВЧ-диапазона. Рассмотрим подробнее каждый из перечисленных здесь видов переключателей [6] .

\section{Переключатели на pin-диодах}

Говоря о ріп-диодных переключателях большой мощности, прежде всего, надо иметь в виду те из них, которые реализованы по кремниевой технологии. Ограничения на максимально допустимую мощность для этих переключателей могут быть связаны как с предельной тепловой мощностью рассеяния $P_{\text {расс' }}$ так и с максимально допустимым напряжением пробоя $V_{\text {пр }}$ которое может вывести ріп-диод из строя.

Мощность рассеяния определяется максимально допустимой температурой диода $\mathrm{T}_{\text {д }}$ (обычно 150 C), превышение которой может привести к деградации характеристик диода, либо к его разрушению. Кроме того, мощность рассеяния определяется тепловым сопротивлением диода $\mathrm{R}_{\mathrm{T}}$ зависящим от конструкции диода и эффективности отвода тепла с его поверхности, а также температурой поверхности $\mathrm{T}_{\mathrm{A}}$, на которой он установлен:

$$
P_{\text {pacc }}=\left(T_{\text {д }}-T_{A}\right) / R_{T}
$$

В случае закрытого ріп-диода максимально допустимая пиковая мощность $P_{\max }$ будет определяться его напряжением пробоя $V_{\text {пр }}$ :

$$
P_{\max }=\left(V_{\text {пр }}-V_{c}\right)^{2} / 8 Z_{0}
$$

где $V_{c}$ - величина напряжения смещения на диоде, $Z_{0}$ - импеданс нагрузки в сечении диода.
На практике основным фактором, ограничивающим максимально допустимую мощность $P_{\max }$ переключателя на ріп-диодах, является напряжение пробоя $V_{\text {пр, посколь- }}$ ку вопросы отведения тепловой мощности от активного прибора могут быть решены различными конструктивными методами. В свою очередь, величина квадрата напряжения пробоя ріп-диода пропорциональна квадрату толщины его i-слоя W. Так как толщина і-слоя ріп-диода во много раз больше длины канала сток-исток полевого транзистора, то потенциально возможные допустимые мощности переключателей на ріп-диодах существенно выше, чем у переключателей на полевых транзисторах.

\section{Переключатели на полевых транзисторах Шоттки}

Уровень переключаемой мощности в переключателях на полевых транзисторах (Пт) зависит от максимально допустимого напряжения на активном элементе в выключенном состоянии и от максимального тока через него во включенном состоянии. На рис. 1 представлены SPDT-переключатель приемопередающего тракта с двумя параллельно включенными ПТ, а также временные зависимости напряжений на стоке и затворе закрытого транзистора. В случае, когда импедансы сток-затвор и затвор-истокприблизительно равны, половина амплитуды переменного напряжения сигнала на стоке $V_{\text {Dmax }}$ оказывается на затворе. Напряжение на затворе с учетом напряжения смещения $V_{c}$ должно быть ниже напряжения отсечки полевого транзистора $V_{p}$ :

$$
-V_{c}+\frac{V_{D \max }}{2}=-V_{p}
$$


Большой размах переменного напряжения сигнала на затворе может привести к деградации или выходу из строя транзисторов. С другой стороны, разница напряжений между стоком и затвором ПТ должна быть меньше или равна напряжению пробоя затвор-сток $V_{\text {в }}$

$$
V_{\text {Dmax }}+V_{c}-\frac{V_{D \max }}{2}=V_{B}
$$

Из уравнений (3), (4) следуют значения максимально возможного напряжения на стоке $V_{\text {Dmax }}$ и требуемое напряжение смещения на затворе $V_{c}$ :

$$
V_{\text {Dmax }}=V_{B}-V_{P}, V_{C}=\left(V_{B}+V_{P}\right) / 2
$$

В результате максимально допустимая мощность, проходящая через параллельно включенный ПТ в выключенном состоянии, будет равна:

$$
\mathrm{P}_{\max }=\frac{\left(\mathrm{V}_{\mathrm{B}}-\mathrm{V}_{\mathrm{P}}\right)^{2}}{2 \mathrm{Z}_{0}}
$$

Когда параллельно включенный в тракт переключателя пт открыт, напряжение на затворе отсутствует и через тран-

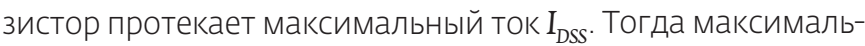
ная мощность рассеивания в транзисторе, нагруженном на импеданс $Z_{0}$, будет равна:

$$
\mathrm{P}_{\max }=\frac{1}{2} \mathrm{I}_{\mathrm{DSS}}^{2} \mathrm{Z}_{0}
$$

Если ограничиться перечисленными условиями, то максимальная коммутируемая мощность будет ограничена несколькими ваттами. Для повышения уровня этой мощности применяют различные схемотехнические решения [6].

Метод трансформации импеданса. Суть метода поясним на примере SPDT-переключателя (рис. 1a), используемого для подключения выхода передатчика (Тх) и входа приемника (Rx) к общей антенне. Максимальная коммутируемая мощность через переключатель проходит в режиме подключения кантенне передатчика. В этом случае ПП закрыт, а ПТ2 открыт. Уровень допустимой мощности в закрытом транзисторе определяется напряжением пробоя затвор-сток $V_{B^{\prime}}$ а в открытом транзисторе - уровнем максимально допустимого тока $I_{\text {DSS. }}$. В соответствии с формулой (6) для увеличения допустимой мощности закрытого транзистора необходимо уменьшить импеданс $Z_{0}$. Решение этой задачи достигается включением между входом антенны с 50-Ом импедансом и местом подключения ее к транзистору низкоомного отрезка линии передачи с волновым сопротивлением (импедансом) $Z_{\text {о1 }}$. В результате этого происходит трансформация импеданса антенны в более низкий импеданс линии передачи в месте ее подключения к транзистору, что приводит к увеличению максимально допустимой коммутируемой мощности при тех же напряжениях пробоя:

$$
P_{\max }=25\left(\frac{V_{B}-V_{P}}{Z_{01}}\right)^{2} .
$$

В свою очередь, включение высокоомного четвертьволнового отрезка линии передачи между антенной и вторым транзистором (ПТ2) позволяет значительно снизить ток через открытый транзистор:

$$
I_{\text {DSS }}=I_{\max }=\frac{\sqrt{100 P_{\max }}}{Z_{02}} .
$$

"Этажерочное" включение транзисторов. Увеличение уровня коммутируемой мощности может быть достигнуто за счет применения широкозатворных полевых транзисторов, включенных в коммутируемую линию параллельно по "этажерочной» схеме (рис. 2). В этом случае напряжение коммутируемого СВЧ-сигнала делится между N параллельно включенными транзисторами. В результате коммутируемая мощность увеличивается в $\mathrm{N}^{2}$ раз:

$$
P_{\max }=\frac{\left[N\left(V_{B}-V_{P}\right)\right]^{2}}{2 Z_{0}} .
$$

Метод резонансного звена. Применение метода трансформации импедансов и "этажерочной» схемы с большим числом транзисторов приводит к увеличению размеров кристалла переключателя. Для устранения этого недостатка был предложен метод с LC резонансным звеном (рис. 3), позволяющий работать при низких управляющих напряжениях и не требующий использования транзисторов с высоким напряжением пробоя.

Рассмотрим этот метод на примере SPDT-переключателя, выполненного по последовательно-параллельной схеме

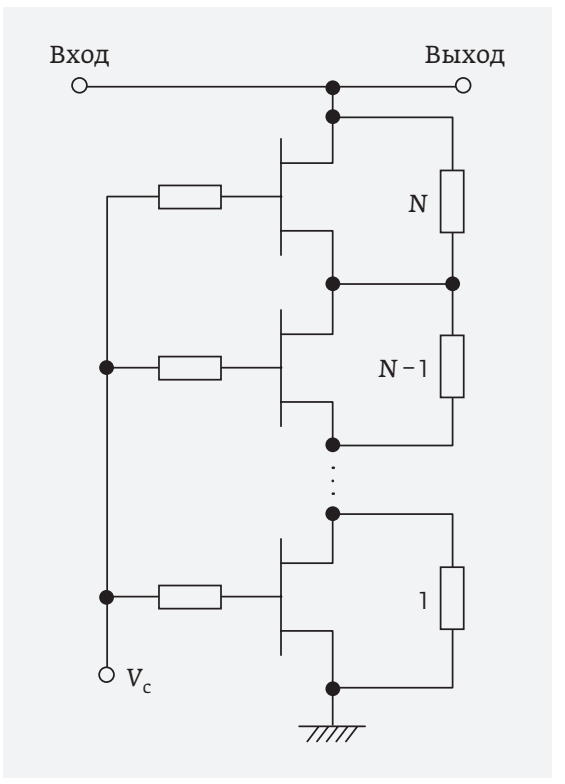

Рис. 2.

"Этажерочная" схема SPSTпереключателя на полевых транзисторах 


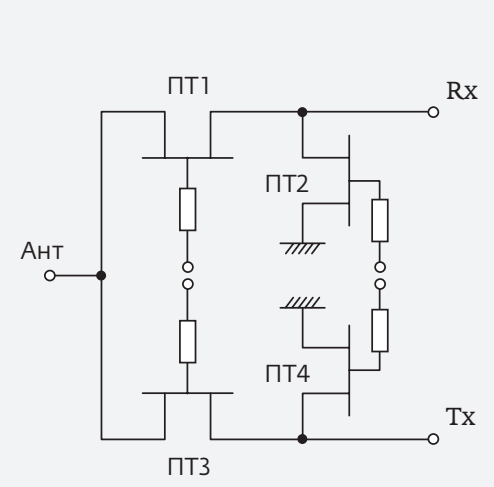

a)

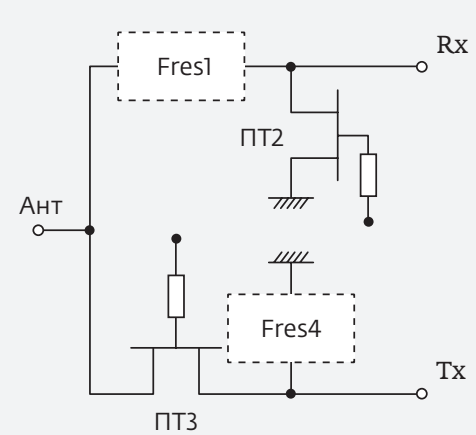

б)

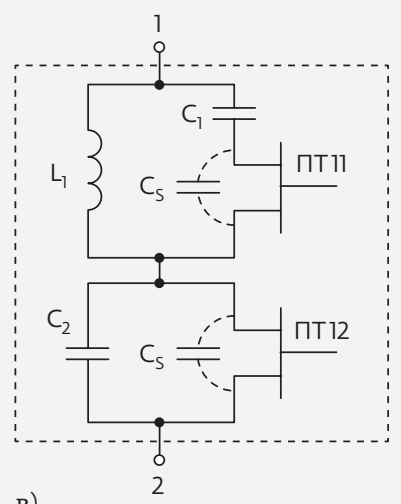

B)
Рис. 3.

Классическая схема SPDTпереключателя на полевых транзисторах (a), схема SPDTпереключателя с двумя резонансными звеньями (б), схема резонансного звена (в) (рис. 3а). Для увеличения максимально допустимой коммутируемой мощности два транзистора - ПТ и Пт4 - заменяются резонансными звеньями (рис. 3б). Каждое из звеньев реализовано на основе двух транзисторов ППТ и ПТ2, причем параллельно первому из них подключена индуктивность $\mathrm{L}_{1}$ а параллельно второму - конденсатор с емкостью $\mathrm{C}_{2}$ (рис. Зв). Последовательно с транзистором Пדі включен конденсатор

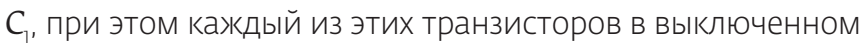
состоянии обладает паразитной емкостью $\mathrm{C}_{\mathrm{s}}$.

Когда транзисторы Пт1 и ПП2 открыты, резонансное звено (рис. Зв) представляет собой параллельный колебательный контур с большим собственным импедансом. Когда транзисторы Пт1 и Пт2 закрыты, звено представляет собой последовательный колебательный контур $L_{1} C_{2}$ с малым импедансом

Преимущество данной схемы, помимо высокого уровня коммутируемой мощности, заключается еще и в том, что для управления используется лишь одна шина, так что все полевые транзисторы открыты в режиме передачи и закрыты в режиме приема. Максимальная коммутируемая мощность в режиме передачи:

$$
P_{\max }=\frac{Z_{0}}{2}\left(\frac{I_{D S S}}{Q_{L}}\right)^{2}
$$

Здесь $\mathrm{Q}_{\mathrm{L}}$ представляет собой нагруженную добротность переключателя в передающем режиме. Использование резонансных звеньев позволяет поднять коммутируемую мощность до 20 раз по сравнению с «этажерочной» схемой на двух полевыхтранзисторах.

\section{Переключатели на GaN HEMT транзисторах}

Основными областями применения нитрид-галлиевых переключателей являются космические системы связи, радиолокаторы с АФАР, базовые станции сотовой связи, схемы защиты входных цепей приемников и медицинское оборудование [7-10].

Среди переключателей наибольшая коммутируемая мощность обеспечивается в изделиях, выполненных на дискретных ріп-диодах. В переключателях на полевых транзисторах достигается наиболее широкий диапазон рабочих частот и высокая скорость переключения. Использование нитрид-галлиевых переключателей с напряжением пробоя в несколько десятков и даже сотен вольт позволяет получить высокие допустимые значения входных мощностей при весьма низких токах управления. Для этих переключателей такжехарактерны высокие скорости коммутации, малые вносимые потери, большие величины развязки, а также большие значения ІІР3, свидетельствующие об их высокой

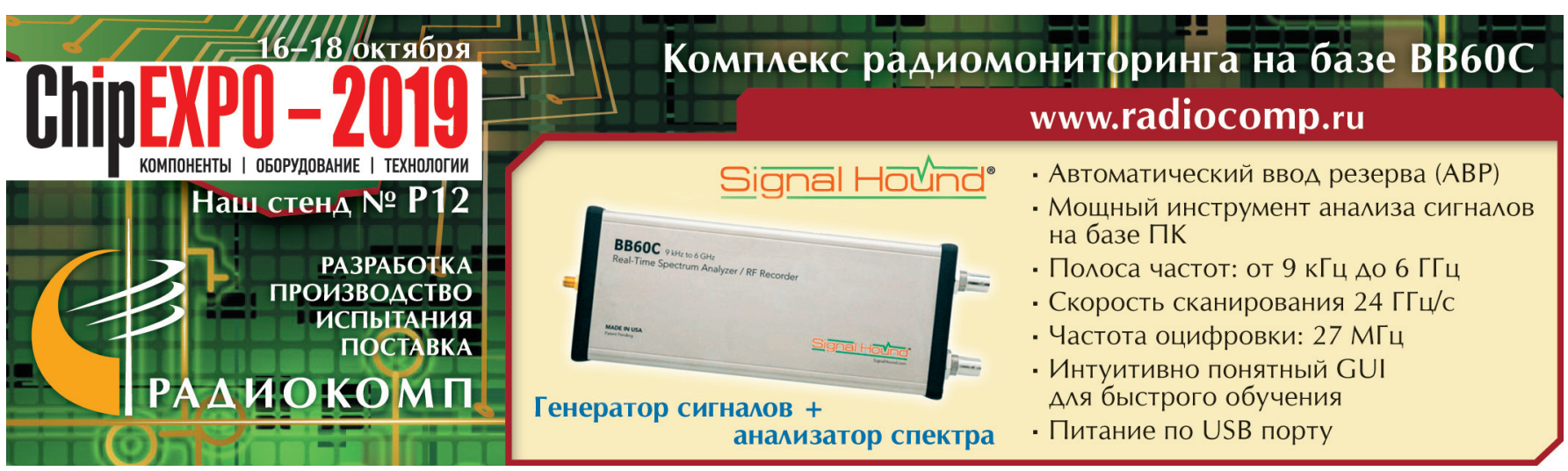




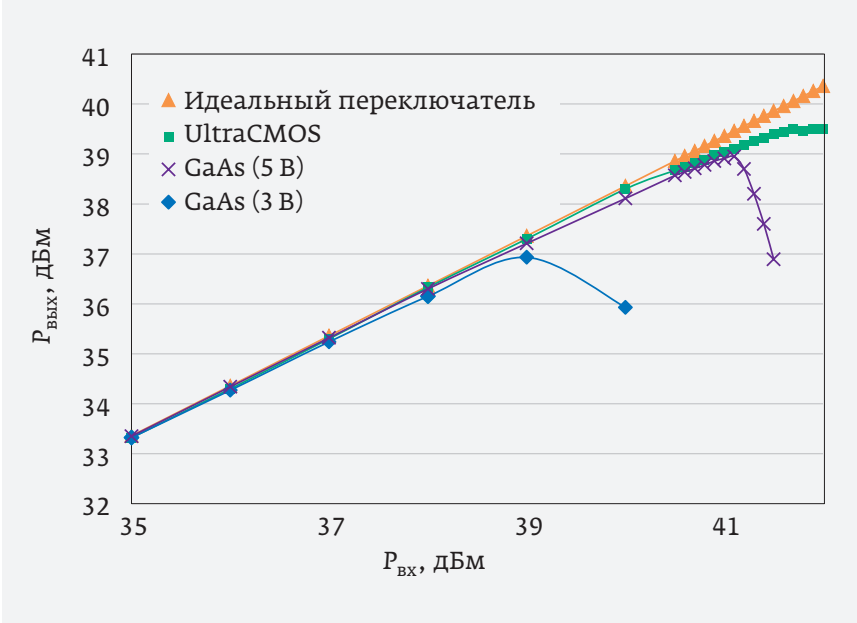

Рис. 4. Зависимость выходной мощности от входной в идеальном переключателе, переключателе по технологии UltraCMOS и в арсенид-галлиевых переключателях с управляющими напряжениями 3 и 5 В

линейности. За счет хорошей теплопроводности подложек на карбиде кремния эти переключатели допускают горячий режим переключения, они могут реализовываться на очень малой площади и, что важно для военных и космических применений, работать в очень широком диапазоне рабочих температур. Срок службы таких переключателей достигает 1 млн часов при температурах переходов в $225^{\circ} \mathrm{C}$ Основным недостатком нитрид-галлиевых переключателей является их высокая стоимость.

\section{Переключатели на кремниевых КМОП-транзисторах}

КМОП-технологии хорошо известны начиная со второй половины 20 века. Изделия, выполненные по этим технологиям, обеспечивали высокую степень интеграции и низкую стоимость, но, ксожалению, отличались низким быстродействием. Все изменилось с использованием новых КМОП-технологий [11-13], базирующихся на применении диэлектрических подложек с высокой степенью изоляции. Основными стали две технологии: КНИ и КНС.

В сравнении с основным своим конкурентом - арсенидгаллиевой технологией, новые кремниевые технологии обеспечили более высокие входные мощности переключателей, большую линейность (рис. 4), сделали возможной их работу на частотах ниже 100 кГц, многократно увеличили степень защиты от электростатических воздействий [14], создали условия для размещения на кристалле вспомогательных компонентов, обеспечивающих функционирование переключателя. Кроме того, более высокая теплопроводность КМОП-изделий в сравнении сарсенид-галлиевыми позволила реализовать КМОП-переключатели на кристаллах с площадью менее 1 мм².
Возможность создания кремниевых пластин с диаметрами, превышающими размеры арсенид-галлиевых пластин, и меньший процент примесей в первых из них обеспечили кремниевым чипам больший выход годных и, как следствие, меньшую стоимость. Практически к настоящему времени КМОП-изделия вытеснили арсенид-галлиевые из коммерческих применений, оставив последним лишь военные и космические приложения. Однако, и в этих областях переключатели, выполненныепо КНС-технологии, вследствие их высокой радиационной стойкости вытесняют арсенидгаллиевые аналоги.

\section{ЛИТЕРАТУРА}

1. Микаэлян А.л. Теория и применение ферритов на сверхвысоких частотах. - М.-Л.: Госэнергиздат, 1963.663 С

2. Кочемасов В. Электромеханические переключатели Вч/СВЧ-сигналов - основные типы и производители // ЭЛЕКТРОНИКА: Наука, Технология, Бизнес. 2016. № 7. С. 114-121, № 8. С. 96-106, № 9. С. 128-134

3. Кочемасов В., Кирпиченков А. Твердотельные СВЧ-переключатели // ЭЛЕКТРОНИКА: Наука, Технология, Бизнес. 2017. № 10. С. 92-97, 2018. № 1. С. 116-124, № 2. С. 150-163.

4. Кочемасов В., Рауткин Ю. Интегральные СВЧ-переключатели // ЭЛЕКТРОНИКА: Наука, Технология, Бизнес. 2018. № 4. С. 122-127, № 5. C. 152-163, № 6. C. 80-93.

5. Кочемасов В., Майстренко А. СВЧ-переключатели на основе МЭМС // СВЧ-электроника. 2016. № 1. С. 36-42.

6. Bahl I.J. Control Components Using Si, GaAs, and GaN Technologies. 2014. Artech House.

7. Kameche M., Drozdovski N.V. GaAs-, InP- and GaN HEMT-based Microwave Control Devices: What is Best and Why // Microwave Journal. May 2005. P. 164.

8. Hangai M., Nishino T., Kamo Y., Miyazaki M. An S-band 100 W GaN Protection Switch. - IEEE MTT-S International Microwave Symposium Digest. 2007. P. 1389-1392.

9. Ma B.Y., Boutros K., Hacker J. B., Nagy G. V. High Power AIGaN / GaN Ku-Band MMIC SPDT Switch and Design Consideration. IEEE MTT-S International Microwave Symposium Digest. 2008. P. 1473-1476.

10. Campbell C.F., Dumka D.C. Wideband High Power GaN on SIC SPDT Switch MMICS. - IEEE MTT-S International Microwave Symposium Digest. 2010, P. 145-148.

11. Li X. J., Zhang Y.P. Flipping the CMOS Switch. - IEEE Microwave Magazine. Febrary 2010. P. 86-96.

12. Swonger J., Bacon P., Wu G. Silicon-on-Sapphire Process Technology Enables Low Power RF Designs. - Microwave Journal. 2012. № 10.

13. Kuzmicz W. The Future of CMOS: More Moore or the Next Big Thing? Proceedings of the $24^{\text {th }}$ International Conference "Mixed Design of Integrated Circuits and Systems». June 22-24. 2017. Bydgoszcz, Poland. P. 21-26.

14. Wang X.S., Wang X., Lu F., et al. Concurrent Design Analysis of High-Linearity SP10T Switch with 8.5 kv ESD Protection // IEEE Journal of solid-state circuits. 2014. V. 49. № 9. P. 1927-1941. 


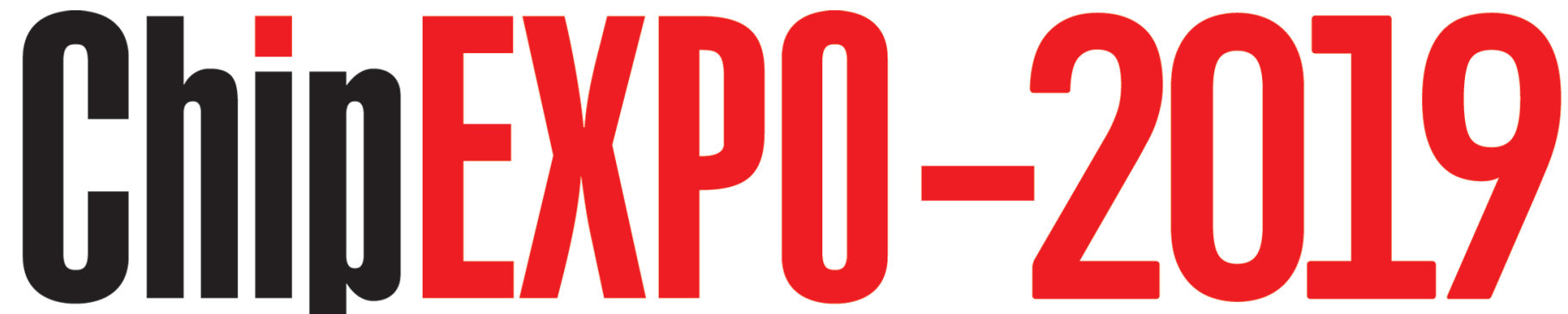

\section{КОМПОНЕНТЫ | ОБОРУДОВАНИЕ | ТЕХНОЛОГИИ}

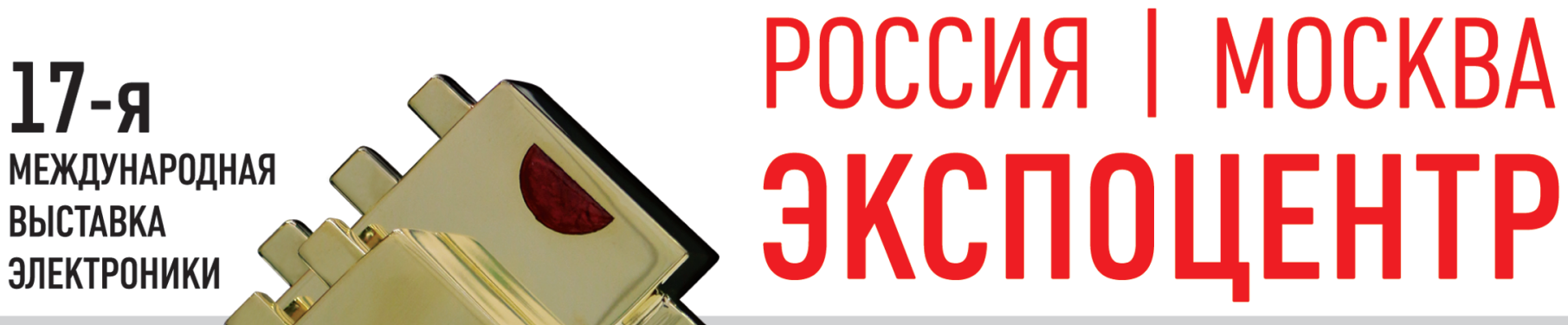

\section{ТЕМАТИЧЕСКИЕ ЭКСПОЗИЦИИ}

- Экспозиция Департамента радиоэлектронной промышленности Минпромторга России «Участники Государственной программы «Развитие электронной и радиоэлектронной промышленности на 2013-2025 годы»

- Экспозиция участников конкурса на присуждение премии «Золотой Чип»

- Экспозиция «Испытания и контроль качества ЭКБ»

- Экспозиция «Новинки производителей электронных компонентов»

- Экспозиция «China electronics»

- Экспозиция предприятий Зеленограда (Корпорация развития Зеленограда]

- Экспозиция предприятий $\mathrm{AO}$ «Росэлектроника»
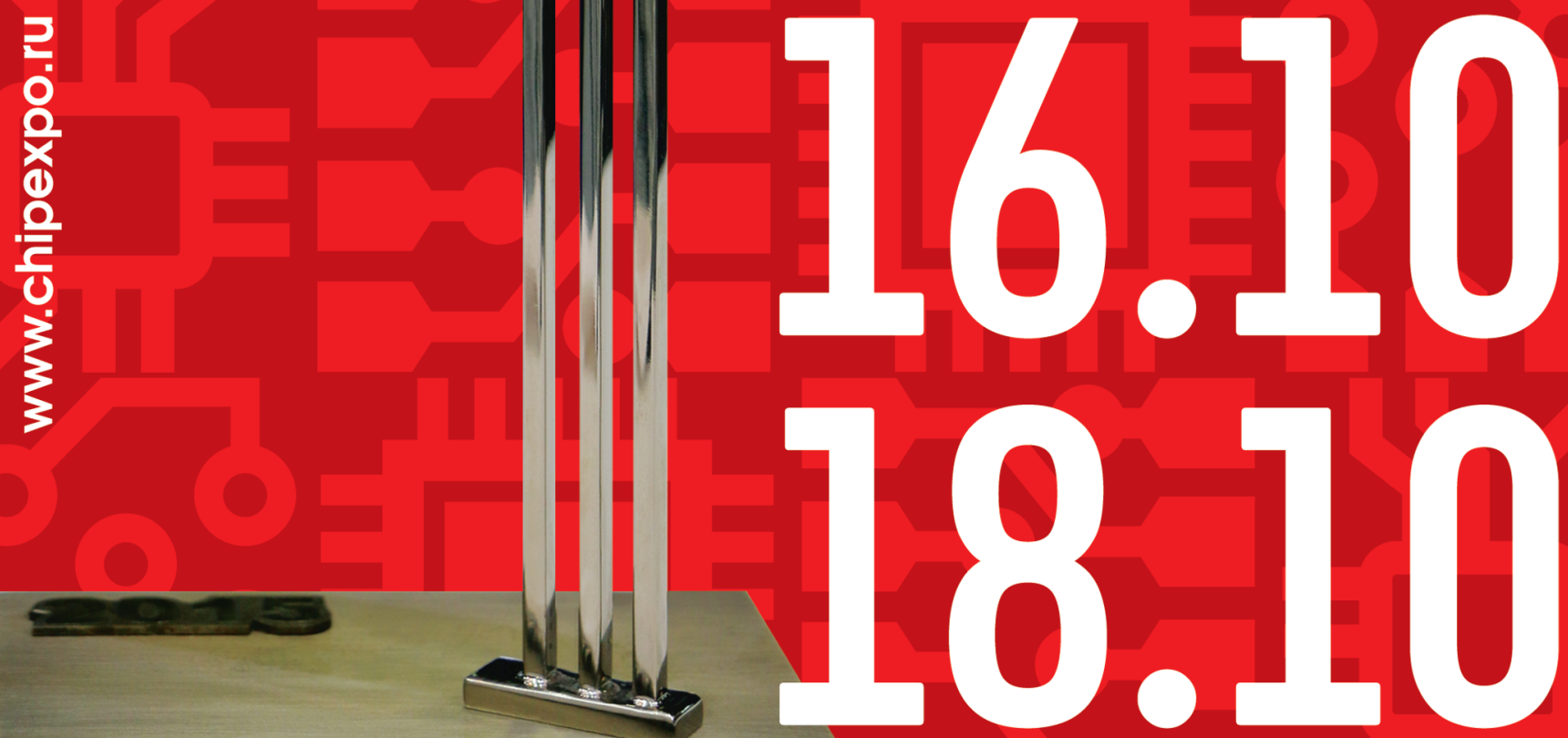

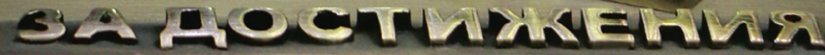
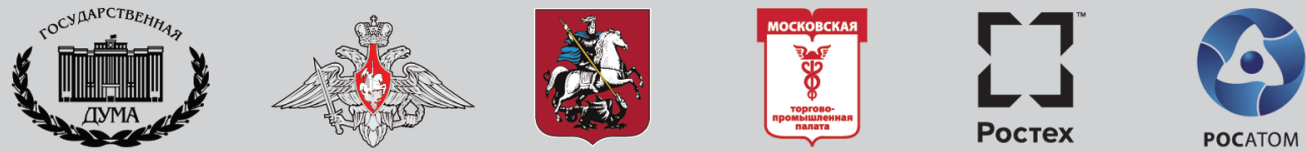